\title{
Spotted Wing Drosophila: Pest Management Recommendations for Southeastern Blueberries ${ }^{1}$
}

\author{
Oscar E. Liburd and Lindsy E. Iglesias ${ }^{2}$
}

The spotted wing drosophila, Drosophila suzukii (Matsumura), is a recently discovered invasive species native to parts of East Asia. It was first detected in the continental United States in California in 2008 and in Hillsborough County, Florida in 2009. Since then, the spotted wing drosophila (SWD) has spread to over 28 counties in Florida. SWD is polyphagous, meaning it feeds on many different host plants, including most thin-skinned fruits. The major hosts of concern to the Florida agriculture industry are blueberries, strawberries, blackberries and grapes. Though crop losses have not yet been quantified in Florida, research in California shows losses as high as 40 percent for blueberries (Bolda et al. 2010) and 20 and 50 percent in strawberries and raspberries, respectively (Goodhue et al. 2011).

\section{Identification, Life Cycle, and Damage}

The spotted wing drosophila is in the family Drosophilidae, also known as the vinegar, fruit, or pomace flies. It shares many physical characteristics with the common vinegar fly, Drosophila melanogaster, which frequents over-ripe and damaged fruits. SWDs have rounded abdomens that are pale yellow to light brown and have dark brown, unbroken horizontal stripes on the dorsal side. They have large, red eyes and sponging mouthparts with which they soak up their food.

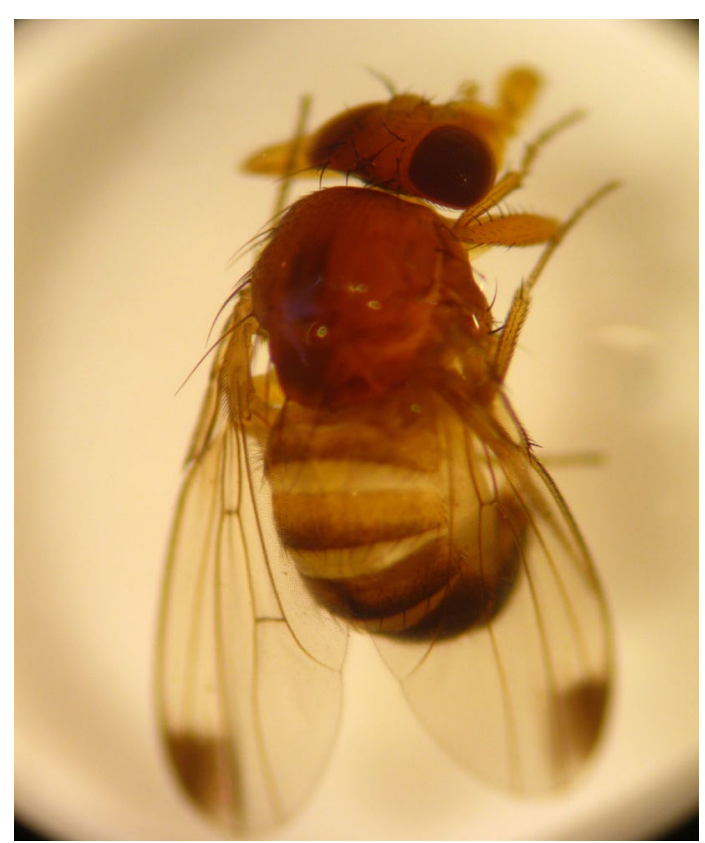

Figure 1. Male SWD.

Credits: L. E. Iglesias

The male flies can be easily distinguished from other vinegar flies by the single dark spot at the tip of each wing (Fig. 1). These spots can be seen with the naked eye or a hand lens in the field. A close relative to D. suzukii is $D$. biarmipes, whose males also have the wingspots. This fly, however, does not pose a threat to ripe fruit because the female's short, weakly sclerotized ovipositor requires over-ripe, soft, or damaged fruit. The SWD can be distinguished from $D$. biarmipes by the two rows of spines

1. This document is ENY-869, one of a series of the Entomology and Nematology Department, UF/IFAS Extension. Original publication date June 2013. Visit the EDIS website at http://edis.ifas.ufl.edu.

2. Oscar E. Liburd, professor of fruit and vegetable entomology, and Lindsy E. Iglesias, graduate research assistant in the Small Fruits and Vegetable IPM laboratory, Entomology and Nematology Department, UF/IFAS Extension Gainesville, FL 32611 
on the forelegs, one on the first tarsal segment and one on the second, whereas D. biarmipes has both rows of spines on the first tarsal segment (Hauser 2011). A hand lens will reveal these spines, which appear as two black horizontal stripes on the forelegs (Fig. 3). Females can be distinguished by comparing the ovipositors.

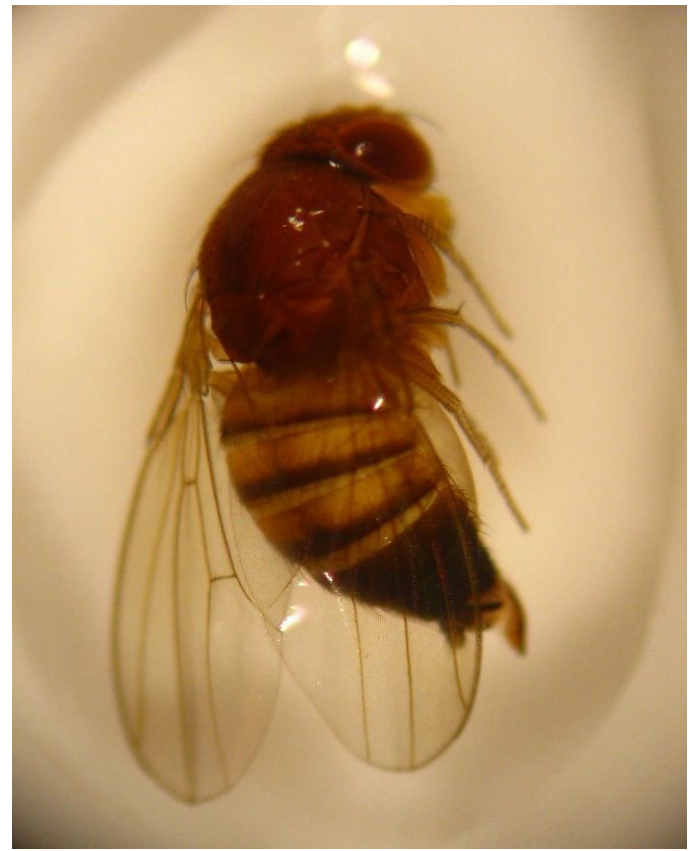

Figure 2. Female SWD.

Credits: L. E. Iglesias

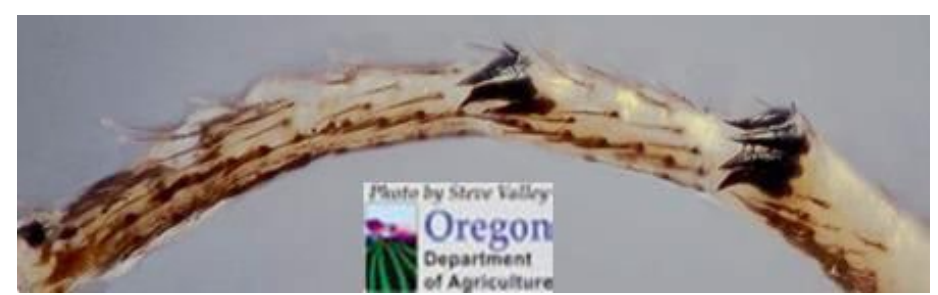

Figure 3. Pair of sex combs on male forelegs (Vlach 2010).

Female SWD are slightly larger than the males and lack the wingspots (Fig. 2). They can be identified by their large, dark, and heavily serrated ovipositor, which they use to pierce the skin of their host fruit to make a place to lay their eggs (Fig. 4). Other Drosophila ovipositors appear rounded, faintly colored, and blunt with small, light teeth compared to SWD's larger, darker, and more heavily serrated ovipositor. The females should be identified using a microscope or at least a strong hand lens.

SWD have been shown to have as many as 15 generations per year when observed in captivity (Kanzawa 1935). These flies can complete their lifecycle in 21 to 25 days and can live for up to 66 days (Kanzawa 1939). The female SWD lays 1 to 3 eggs per oviposition site, with an average of 380 eggs throughout her lifetime. Multiple female SWD can lay

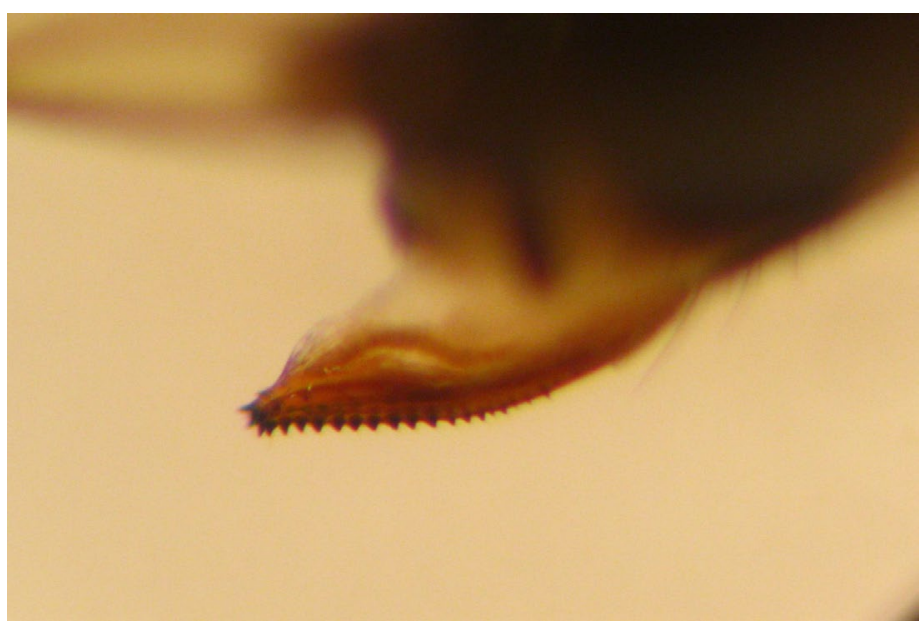

Figure 4. Female SWD ovipositor is dark with well-developed teeth.

Credits: L. E. Iglesias

eggs on a single fruit, resulting in large numbers of larvae injuring one berry.

The eggs of SWD are milky white, oblong, and approximately $0.5 \mathrm{~mm}$ by $0.2 \mathrm{~mm}$ (Kanzawa 1935). They have two long, thread-like appendages used for breathing that protrude from the skin of the blueberry. These can be seen with a microscope or a strong hand lens. Eggs generally hatch after 1 to 3 days inside the berry.

The larvae of SWD are very similar to those of other Drosophila and are extremely difficult to identify even by trained professionals. They are thin, white, and soft-bodied with pointed anterior and posterior ends (Fig. 5). Their mouthparts appear black on the anterior end. SWD have 3 larval stages that all take place inside of the berry. The full larval stage generally lasts 4 to 5 days (Kanzawa 1935).

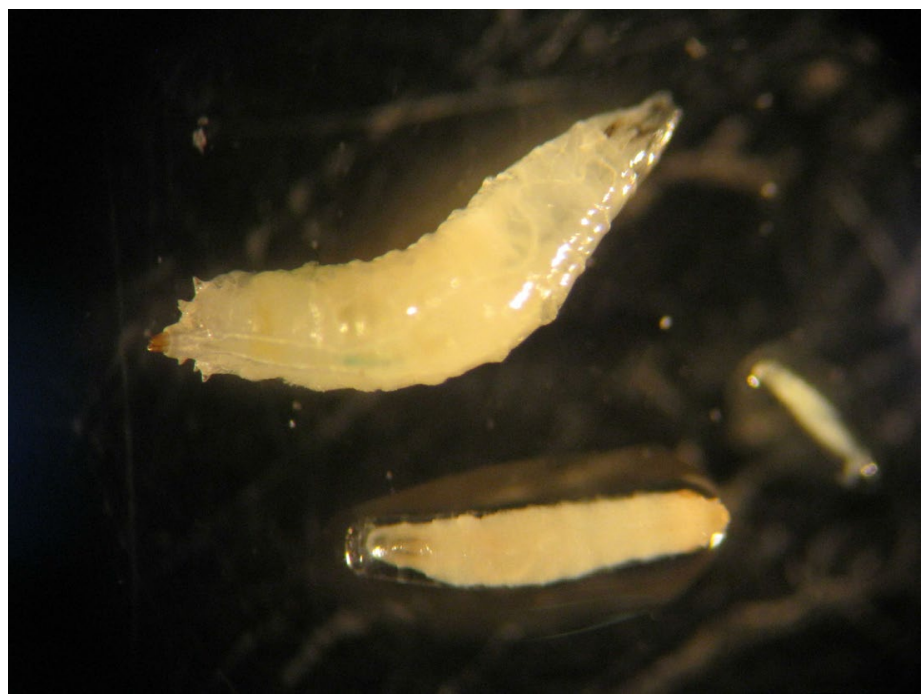

Figure 5. SWD larval instars. Clockwise from right, first, second, and third instars.

Credits: L. E. Iglesias 
SWD pupae are oblong and range from light brown to dark brown as they develop (Fig. 6). Spiked protrusions on the anterior end of the pupae are used as breathing apparatuses. As the pupae get closer to eclosion, or emergence, the red eyes and wings of the fly can be seen through the pupal case. Pupation can occur in the soil, inside the fruit, or on the surface of the fruit. It generally occurs within 4 to 5 days (Kanzawa 1935).

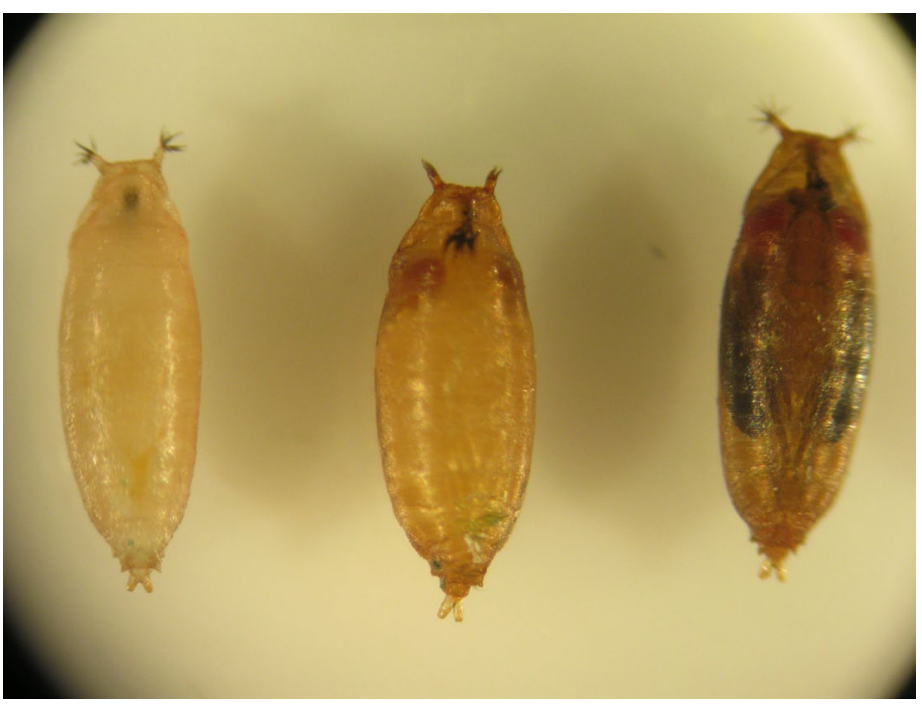

Figure 6. Three pupal instars. From left, first, second, and third instars. Credits: L. E. Iglesias

\section{SWD Management Program}

Our management program is focused on 1) effective monitoring, 2) cultural control and 3) use of selective pesticides.

\section{Adult Monitoring}

SWD will oviposit, or lay eggs, on fruit that are still maturing, and therefore monitoring should begin as the green berries begin to change to pink. Hang traps in the center of the blueberry bush in a shady area at a minimum of 2 traps per 5 acres (Fig. 7). Hang most of the traps along the perimeter of the field but do place a few of them towards the center. Since organic growers are unable to use chemicals to induce a more uniform ripening, they will need to monitor for ripeness frequently and resituate traps so that they are placed in areas where the berries have begun to turn from green to pink. Service traps at least once per week by collecting the samples and replacing with fresh bait.

The trap recommended for SWD monitoring is a plastic cup trap made from a $32 \mathrm{oz}$ plastic cup and lid with 8 to $10 \frac{1 / 4}{4}$-inch holes along the upper rim (Fig. 8). A twist tie is

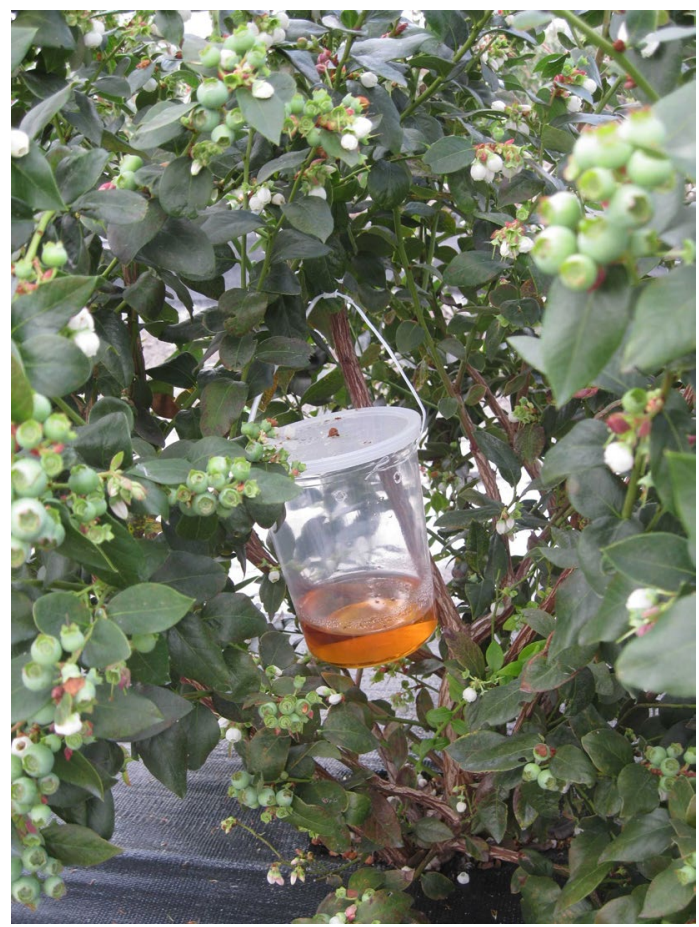

Figure 7. Trap hung in shady interior of a blueberry bush. Credits: L. E. Iglesias

used to hang the trap in the center of the bush in the shade. Some trap designs include a yellow sticky card inside the trap; we have found that captures do not increase with the addition of the card.

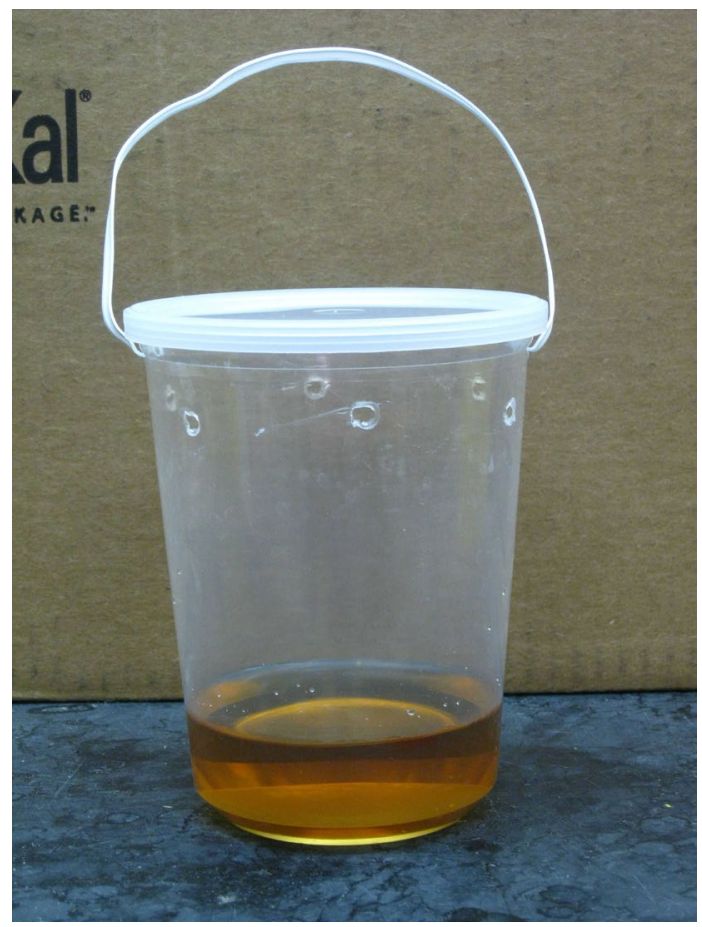

Figure 8. Plastic cup trap with 8 to 10 1/4-in holes and a lid. Trap baited with apple cider vinegar.

Credits: L. E. Iglesias 
Traps are baited with approximately 1.5 to 2 inches $(150 \mathrm{ml})$ of either apple cider vinegar or a yeast-sugar-water mixture. Two drops of odorless dish soap can be added to the apple cider vinegar to break the surface tension of the vinegar and help prevent fly escape. The yeast-sugar-water mixture is made of $0.25 \mathrm{oz}$ yeast, 4 tsp sugar, and $300 \mathrm{ml}$ water (Bolda 2009). The yeast mixture has shown to be more effective at capturing SWD than the apple cider vinegar when conditions are warm. In cooler conditions, results suggest that the yeast mixture may not react as intensely and the vinegar may perform better. The vinegar is also inexpensive, easy-to-use, and specimens can be identified easily.

\section{Larval Monitoring}

Monitoring for larvae is done using the salt test. Randomly collect at least 30 healthy, undamaged berries from your field and place in a resealable plastic bag. SWD prefer to lay eggs in healthy, undamaged fruit rather than over-ripe, damaged fruit, so it is unlikely that larvae found would be another Drosophila species. Mix a salt solution of $1 / 4$ cup salt to 4 cups water. Lightly crush the berries in a bag and add the salt solution. Allow the fruit to sink to the bottom of the bag (approximately 10-15 $\mathrm{min}$ ). If the fruit is infested, the larvae should float to the top. Monitor fruit for larvae each week.

Larvae can also be monitored by collecting berries from the field and placing them into a container. The container should be placed at room temperature with $60-70 \%$ relative humidity and adults should emerge from any infested fruit. This procedure will allow a more accurate identification of SWD. However, this may delay treatment actions because it takes 10-14 days before adults emerge.

\section{Cultural Control}

1. Sanitation - Sanitation is one of the most important cultural control methods available to growers for the control of SWD outbreak in blueberries. When possible, remove fallen berries from the field and solarize using clear or black plastic bags or mulch. The culls may be harboring SWD larvae or pupae that will emerge to lay eggs in the ripe fruit.

2. Frequent Harvest Intervals - In addition to sanitation practices, frequent harvest intervals will keep susceptible fruit off of the bushes and help to reduce the SWD population and prevent outbreaks. During the peak of harvest season, harvest intervals can be between 2 and 3 days.
3. Exclusion Netting - Mesh netting can help prevent SWD infestation in blueberries when hole size is less than 1 $\mathrm{mm}$. It will reduce entry into the field by 100 percent when the mesh size is less than $0.98 \mathrm{~mm}$ (Kawase and Uchino 2005). Wait until pollination is complete to place the netting so that bees and other pollinators will have entry into the field. Netting can be an expensive and labor-intensive option for large blueberry growers but may prove more viable for small or organic growers. Because organic growers cannot use chemicals such as Dormex ${ }^{\otimes}$ to induce more uniform ripening, netting can be applied in sections to cover only those varieties that have begun to ripen and leave flowering varieties uncovered for pollination.

\section{Chemical Control}

A decision to spray should be based entirely on monitoring data. This data could be obtained from monitoring traps or it could be based on larval counts from berries. The problem with data taken from larval counts is that by the time these data are available it is usually too late for spraying and a large percentage of the field could be infested. Regardless, once SWD is recorded in the planting, the grower should embark on a spraying program. Table 1 provides a list of insecticides for SWD control. During spraying, growers should aim for a 10- to14-day cycle, and the same product should not be used more than two times in a row before rotating to a different class. Rotating among the various classes delays the onset of resistance to the pesticides that are used in the management program. When using pesticides, the grower must follow the label and take care to use selective pesticides that do not harm bees or other pollinators. Therefore, pesticides should be applied only in the late evening or early morning, when beneficial insects including bees are less active. Keep monitoring regularly for adults and larvae during the application of pesticides.

\section{References}

Bolda M., R. E. Goodhue, and R. G. Zalom. 2010. [SWD]: Potential economic impact of a newly established pest. Giannini Foundation of Agric. Econ., UC 13: 5-8. http:// www.agecon.ucdavis.edu/extension/update/articles/ v13n3_2.pdf

Bolda, M. 2009. A Comparison of Torula Yeast, Yeast + Sugar + Water and Commercial Filth Fly Mix. Agriculture and Natural Resources, University of California. Visited February 8, 2013 http://ucanr.org/blogs/blogcore/postdetail.cfm?postnum $=1985$ 
Goodhue, R.E., M. Bolda, D. Farnsworth, J.C. Williams, and F.G. Zalom. 2011. [SWD] infestation of California strawberries and raspberries: Economic analysis of potential revenue losses and control costs. Pest Manage. Sci. 67:1396-1402.

Hauser, M. 2011. A historic account of the invasion of Drosophila suzukii (Matsumura) (Diptera: Drosophilidae) in the continental United Stated, with remarks on their identification. Pest. Manag. Sci. 67:1352-1357.

Kanzawa, T. 1935. Research on the fruit-fly Drosophila suzukii (Matsumura): Preliminary report. Yamanashi Prefecture Agric. Exp. Sta. p. 42.
Kanzawa, T. 1939. Studies on Drosophila suzukii Matusumura. Kofu, Yamanashi Agric. Exp. Sta. p. 49.

Kawase, S., and K. Uchino. 2005. Effect of mesh size on Drosophila suzukii adults passing through the mesh. Ann. Rep. Kanto-Tosan Plant Prot. 52:99-101.

Vlach, J. 2010. Identifying Drosophila suzukii. Oregon Department of Agriculture. Visited on February 9, 2013. http://www.oregon.gov/ODA/PLANT/docs/pdf/ ippm_d_suzukii_id_guide10.pdf

Table 1. Insecticides recommended for spotted wing drosophila management

\begin{tabular}{|c|c|c|c|c|}
\hline Active Ingredient & Trade Name & REI $^{1}$ & $\mathbf{P H I}^{2}$ & Mode of Action Code ${ }^{3}$ \\
\hline Azadirachtin* & Neem Oil & 4 hours & 0 hours & UN \\
\hline Bifenthrin & Brigade & 12 hours & 0 days & $3 \mathrm{~A}$ \\
\hline Fenpropathrin & Danitol & 24 hours & 3 days & $3 \mathrm{~A}$ \\
\hline Malathion & Malathion & 12 hours & 1 days & $1 B$ \\
\hline Phosmet & Imidan & 1 day & 3 days & 1B \\
\hline Pyrethrins* & PyGanic & 12 hours & 0 hours & $3 \mathrm{~A}$ \\
\hline Spinetoram & Delegate & 4 hours & 3 days & 5 \\
\hline Spinosad* & Entrust & 4 hours & 3 days & 5 \\
\hline Zeta-Cypermethrin & Mustang Max & 12 hours & 1 day & $3 \mathrm{~A}$ \\
\hline \multicolumn{5}{|c|}{$\begin{array}{l}{ }^{1} \mathrm{REI} \text { - Re-entry interval--the period that must pass between application of the selected insecticide and entry of any persons into the treated } \\
\text { area. } \\
{ }^{2} \mathrm{PHI} \text { - Pre-harvest interval--the period that must pass between the application of a selected insecticide and harvest of the crop. ALWAYS follow } \\
\text { label instructions. } \\
{ }^{3} \text { For management of spotted wing drosophila (SWD) resistance to insecticides, growers should use products from one mode of action group } \\
\text { during the period of one SWD lifecycle, then rotate to another mode of action for a similar period. } \\
{ }^{*} \text { Labeled for Organic Use }\end{array}$} \\
\hline
\end{tabular}

